\title{
Differences Between Men and Women in Markers of Fatty Acid Oxidation
}

\author{
Catriona A McNeil, Camilla Pramfalk, Michael Pavildes, Fredrik Karpe and \\ Leanne Hodson
}

\section{BACKGROUND AND AIMS}

Men have a higher prevalence of non-alcoholic fatty liver disease (NAFLD) than women. The reason for this remains unclear but it could, in part, be due to the availability and removal of fatty acids (FA) from the liver. As the transition from fasted to fed state may fundamentally alter hepatic FA partitioning we aimed to study hepatic FA partitioning in healthy men and women before and after the consumption of a mixed meal.

\section{MATERIALS AND METHODS}

- Twenty-two healthy men $(n=11)$ and women $(n=11)$ that were similar in age, BMI and liver fat content were recruited (Table 1).

* Participants consumed deuterated water $\left(\left({ }^{2} \mathrm{H}_{2} \mathrm{O}\right) 3 \mathrm{~g} / \mathrm{kg}\right.$ body water) the evening prior to study day and continued to consume enriched water $(2.5 \mathrm{~g} / 500 \mathrm{ml})$ over the course of the study day. After baseline blood and breath samples were taken, participants were fed a standard test meal consisting of $40 \mathrm{~g}$ fat (labelled with $200 \mathrm{mg}\left[\mathrm{U}^{13} \mathrm{C}\right]$ palmitic acid) and $40 \mathrm{~g}$ carbohydrate. At 360 minutes a glucose $(75 \mathrm{~g})$ drink was given to assess the second meal effect.

Table 1. Characteristics of Participants

\begin{tabular}{lcc}
\hline & Women $(\mathrm{n}=11)$ & Men $(\mathrm{n}=11)$ \\
\hline Age $(\mathrm{y})$ & $46 \pm 2$ & $46 \pm 2$ \\
Body Mass Index $\left(\mathrm{kg} / \mathrm{m}^{2}\right)$ & $28 \pm 1$ & $27 \pm 1$ \\
Liver fat $(\%)$ & $4.1 \pm 1.0$ & $4.6 \pm 0.9$ \\
Fasting plasma concentrations & & \\
Triacylglycerol $(\mathrm{mmol} / \mathrm{l})$ & $1.0 \pm 0.2$ & $1.7 \pm 0.3^{*}$ \\
Glucose $(\mathrm{mmol} / \mathrm{L})$ & $5.0 \pm 0.1$ & $5.0 \pm 0.3$ \\
Insulin $(\mathrm{mU} / \mathrm{L})$ & $11.4 \pm 1.9$ & $10.8 \pm 0.8$ \\
Non-esterified fatty acids $(\mu \mathrm{mol} / \mathrm{L})$ & $488 \pm 37$ & $445 \pm 34$ \\
3-hydroxybutyrate $(\mu \mathrm{mol} / \mathrm{L})$ & $67 \pm 11$ & $55 \pm 9$ \\
Acetoacetate $(\mu \mathrm{mol} / \mathrm{L})$ & $42 \pm 7$ & $38 \pm 4$ \\
VLDL-TG $(\mu \mathrm{mol} / \mathrm{L})$ & $607 \pm 124$ & $997 \pm 131^{*}$ \\
\hline Data presented as mean+sem ${ }^{*} \mathrm{P}<0.05$ & &
\end{tabular}

* Blood samples were collected at $0,30,60,90,120,180$, 240, 300, 360, 390, 420 minutes for biochemical and stable-isotope analysis.

* Hepatic dietary FA oxidation was measured by incorporation of ${ }^{13} \mathrm{C}$ into plasma 3-hydroxybutyrate (3OHB) by Gas Chromatography Mass Spectrometry (GCMS)

* Whole body FA oxidation was assessed by the appearance of ${ }^{13} \mathrm{C}$ (from dietary fat) into expired breath $\mathrm{CO}_{2}$ using GC-Combustion-Isotope Ratio Mass Spectrometry (GC-C-IRMS)

* Hepatic DNL was measured by the incorporation of ${ }^{2} \mathrm{H}$ into palmitate within VLDL-TG using GCMS

\section{RESULTS}

- Despite having similar liver fat content men had significantly higher fasting and postprandial plasma TG and VLDL-TG (Table 1 and Figure $2 \mathrm{~A}$ )

* No sexual-dimorphism was observed in appearance of ${ }^{13} \mathrm{C}$ (from dietary fat) into VLDL-TG (data not shown).

- Despite no difference in the fasting concentrations of plasma acetoacetate and 3OHB between women and men (Table 1), after consumption of the test meal women had significantly higher concentrations of plasma acetoacetate and $3 \mathrm{OHB}$ than men (Figure 2B-C).

* Over the course of the postprandial period women had significantly higher incorporation of ${ }^{13} \mathrm{C}$ (from dietary fat) into plasma $3 \mathrm{OHB}$ (Figure 3A) and had a significantly higher production of ${ }^{13} \mathrm{CO}_{2}$ (Figure 3B) than men.

- Although the contribution of newly synthesised (de novo) palmitate to VLDL-TG was similar between women and men in the fasting state, there was a divergence in response during the course of the postprandial period, with men maintaining a significantly higher contribution than women (Figure 3C).

Figure 2. Unlabelled Postprandial Results
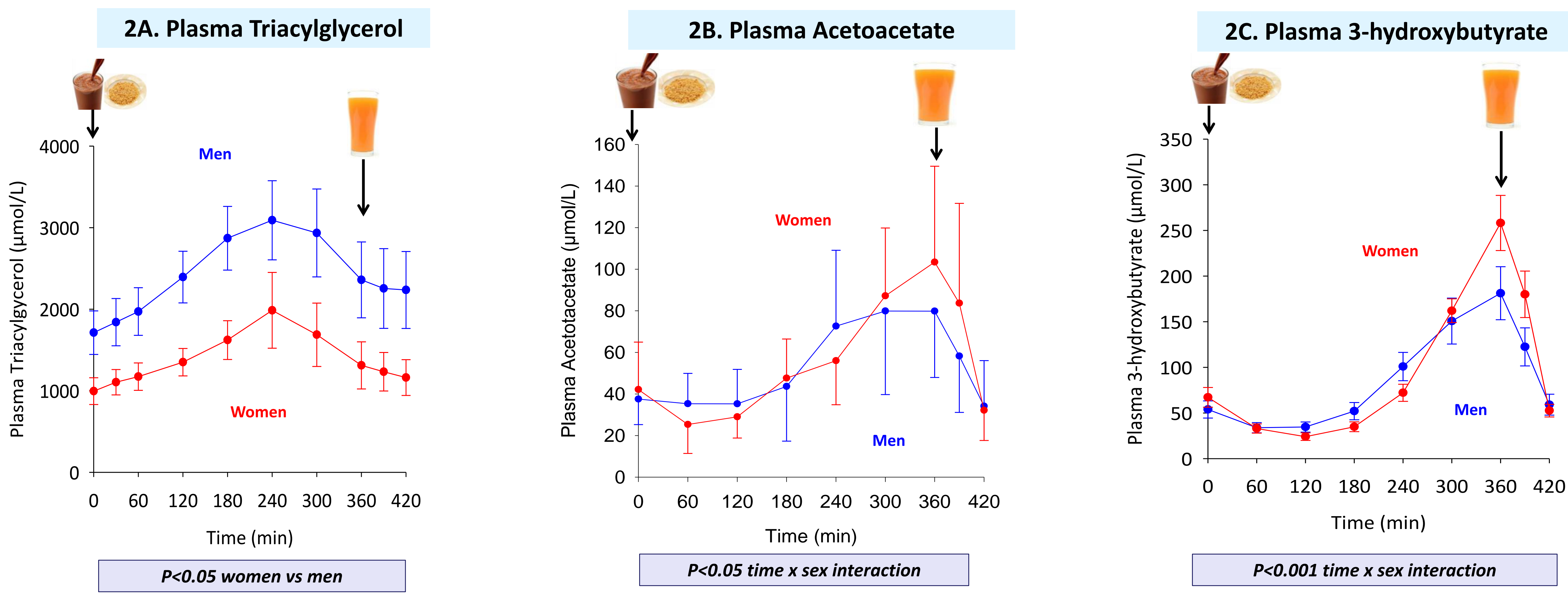

\section{CONCLUSIONS}

The data demonstrates that women tend to favour oxidation pathways while men tend to favour synthetic pathways. Notable differences observed in markers of dietary FA oxidation in the post prandial period showed that recently ingested FA were utilised for ketogenesis at a greater extent in women compared to men and ${ }^{13} \mathrm{CO} 2$ production (per unit lean mass) was significantly higher in women whilst men had higher levels of DNL in the post prandial period compared to women. The combination of lower dietary fatty acid oxidation and prolonged increase in DNL may explain, in part, the prevalence of hepatic steatosis in men.

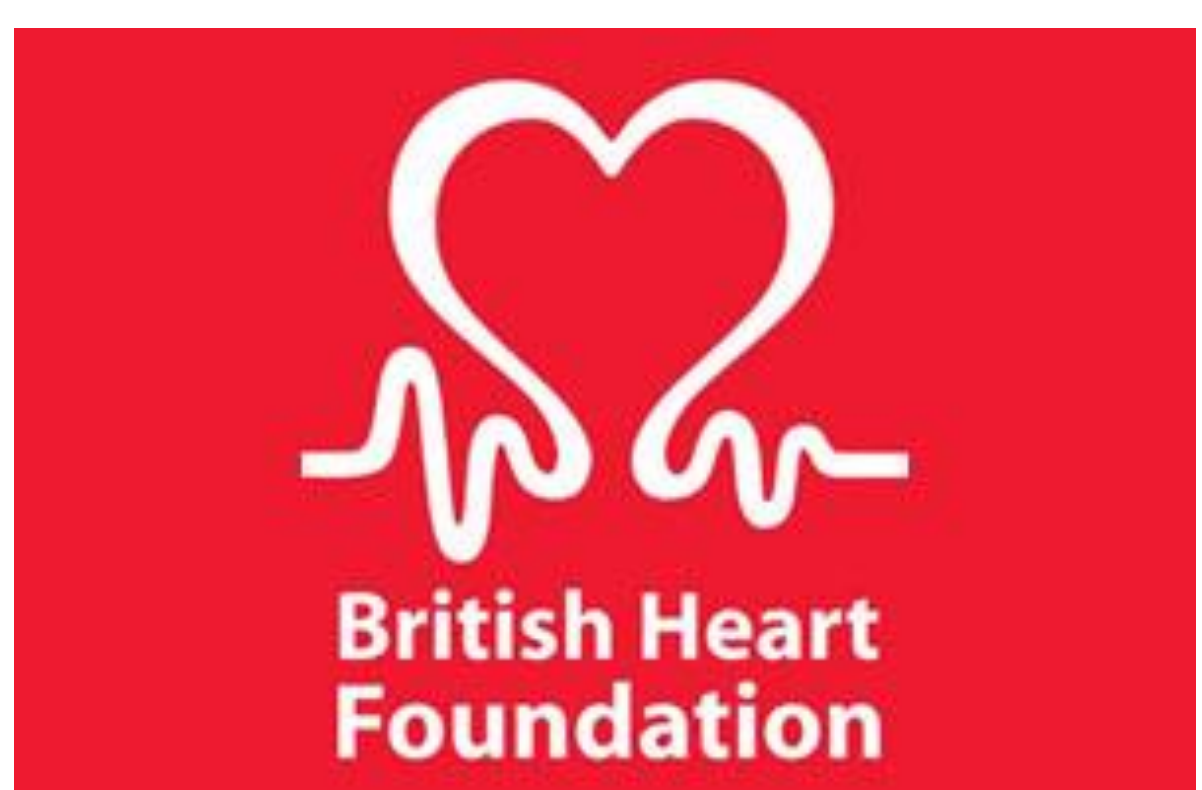

This work was supported by the British Heart Foundation

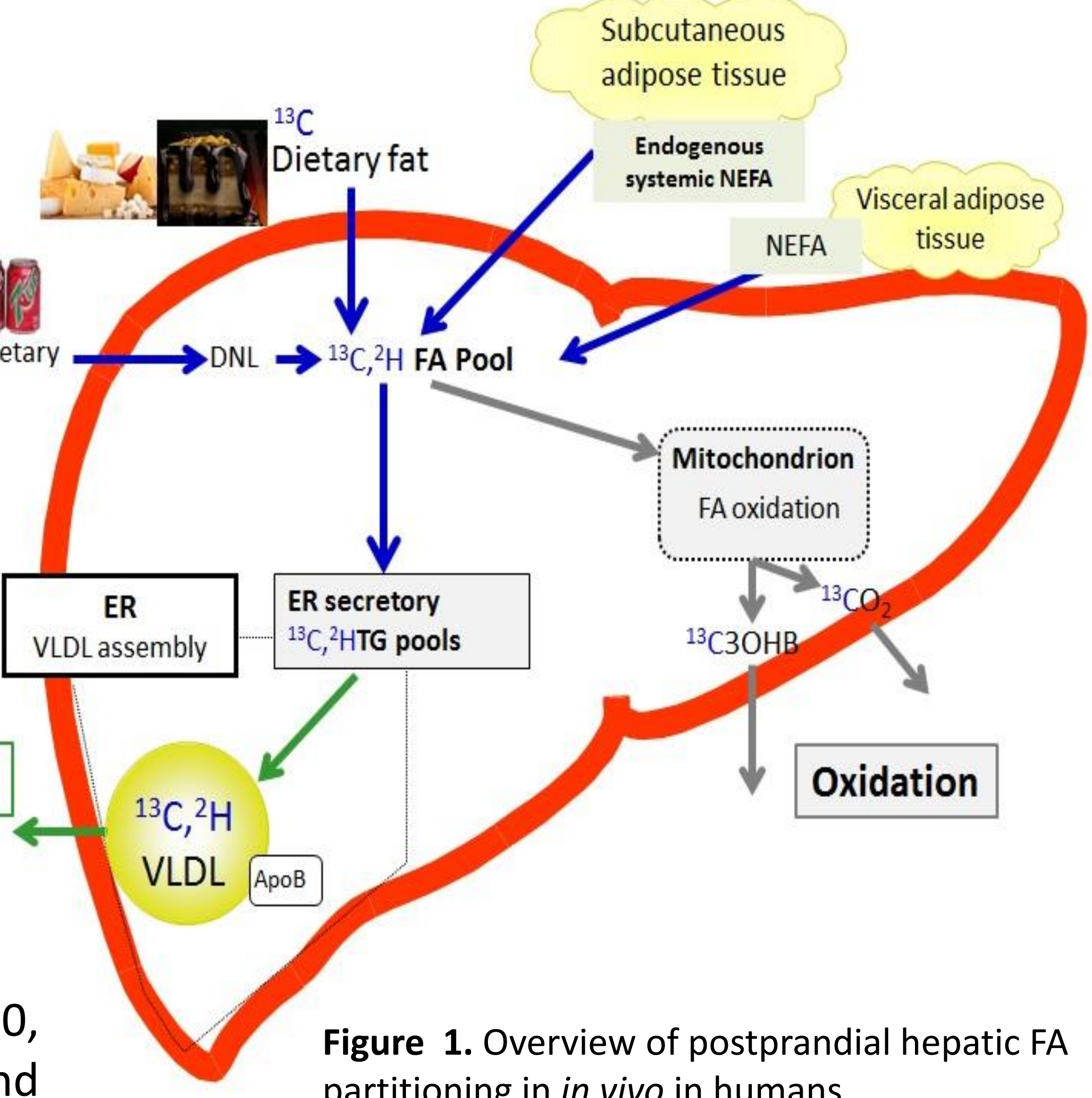

partitioning in in vivo in humans.

Figure 3. Labelled Postprandial Results
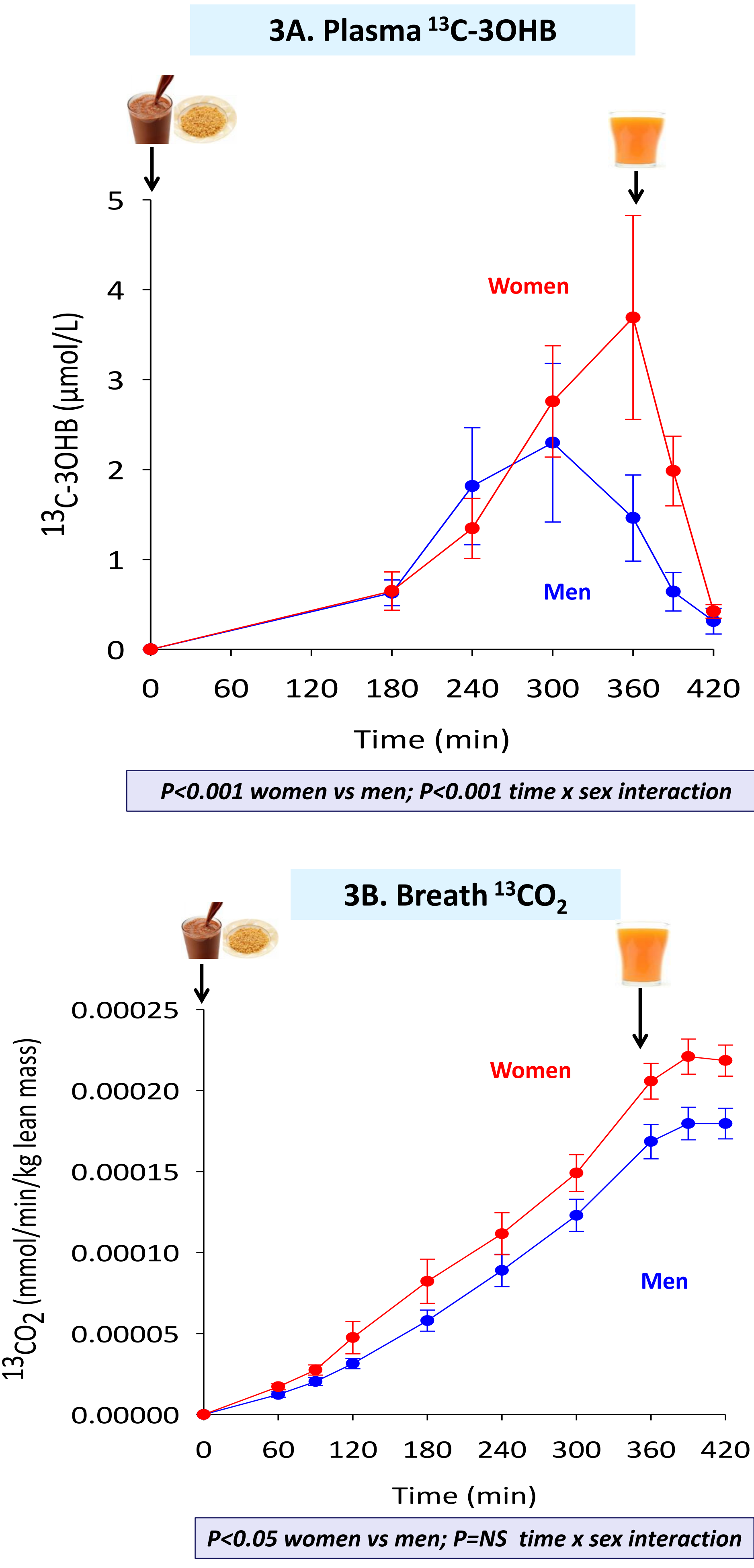

3C. Hepatic DNL

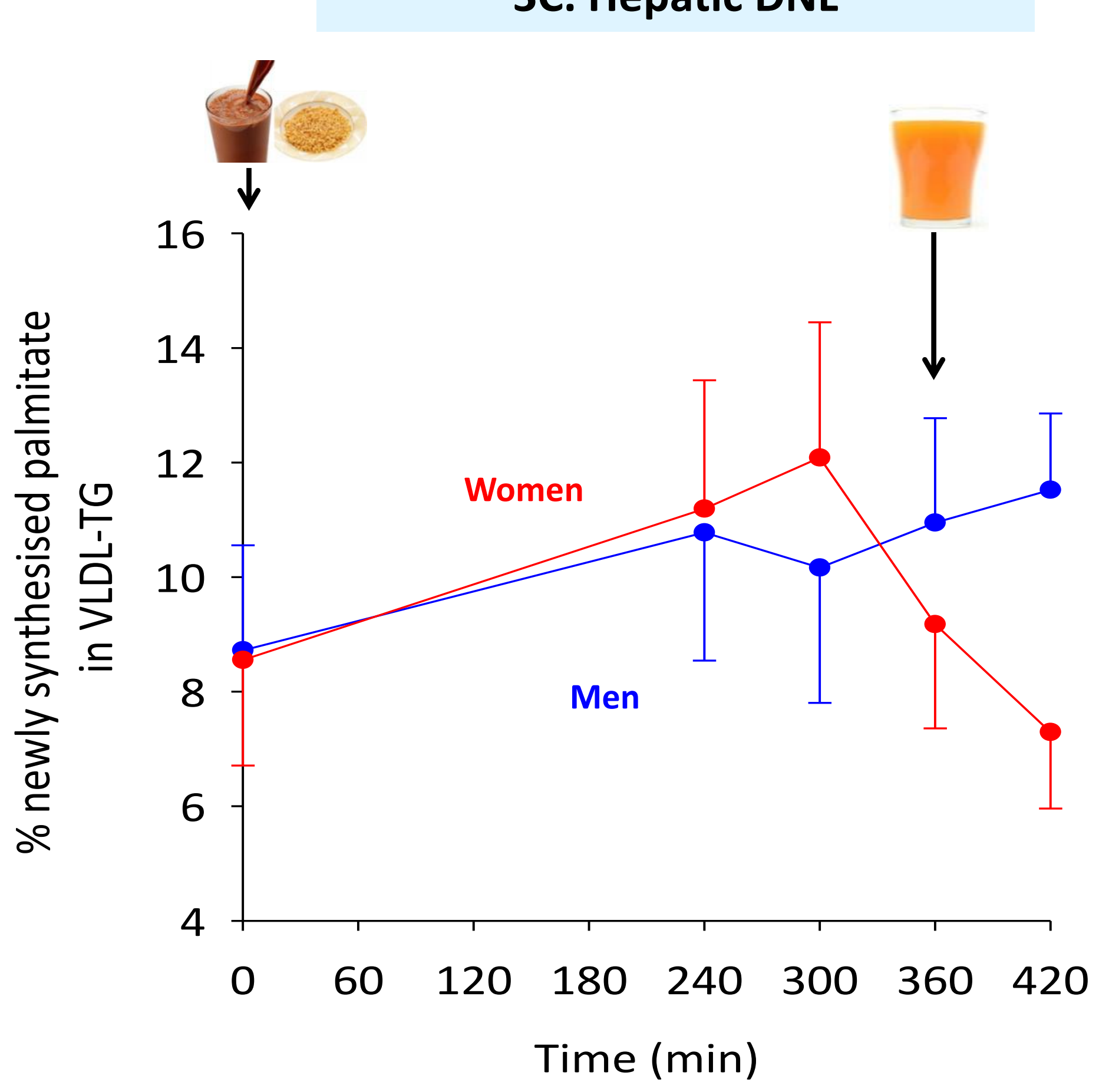

$P=N S$ women vs men; $P<0.00$ time $x$ sex interaction 